\title{
Comparison Between Temporal Versus Nasal Anterior Transposition of the Inferior Oblique Muscle for Management of Dissociated Vertical Deviation with Inferior Oblique over Action: Two Years Follow Up
}

\author{
Mahmoud M Saleh and Nour Elden A Abdelhalim \\ Department of Ophthalmology, Al-Azhar University, Cairo, Egypt \\ * Corresponding author: Mahmoud Saleh, e-mail:Shahdmsaleh@ hotmail.com.
}

\begin{abstract}
Background: anterior nasal transposition (ANT) is a relatively new procedure which can be used to eliminate inferior oblique over action. An advantage of this procedure over temporal anterior transposition is that it avoids ante-elevation syndrome.
\end{abstract}

Objective: to compare anterior temporal transposition (ATIO) of the inferior oblique muscles versus anterior nasal transposition (ANT) in management dissociated vertical deviation (DVD) with inferior oblique muscle over action (IOOA).

Patients and Methods: The study included 50 eyes of 28 patients with DVD of at least 10 prism dioptres $\Delta$ in the eye involved. The patients were divided into two groups. Group A (25 eyes of 15 patients) managed by temporal anterior transposition (ATIO) of the inferior oblique muscles and Group B (25 eyes of 13 patients) managed by nasal anterior transposition (ANT) of the inferior oblique muscles. All patients were followed for at least 24 months postoperatively. The size of preoperative and postoperative angle of DVD, grade of IOOA preoperative and postoperative, need for repeated surgeries and complications were recorded and evaluated.

Results: In group A the mean DVD angle was decreased in primary positions from $21.11 \pm 4.32 \Delta$ to 9.5 $\pm 4.7 \Delta(P<0.001)$ and from $19.5 \pm 4.6 \Delta$ to $5.51 \pm 2.65 \Delta(P<0.001)$ in group B mean IOOA grade was decreased from $+2.0 \pm 0.7$ to $+0.18 \pm 0.4$ in group A $(P<0.001)$ and from $+2.5 \pm 0.7$ to $+0.1 \pm 0.5(P<0.001)$ in group B. In group B, two patients developed hypotropia of 5 and 6 PD. Persistent IOOA $(+1)$ was observed postoperatively in two eyes in each group. Limited elevations in abduction developed in 3 patients in group A, the incidence of recurrence rate after 24 months was 2 eyes $10 \%$ in group A and one eye $5 \%$ in group B.

Conclusion: Anterior transpositions either temporal or nasal of the inferior oblique muscles are safe and effective in management of DVD with inferior oblique muscle over action. Anterior nasal transposition (ANT) is more effective in correction of DVD with less incidence of antielevation syndrome and recurrence of DVD, however may induce persistent hypotropia.

Keyword: DVD, IOOA, ATIO and ANT.

\section{INTRODUCTION}

Dissociated vertical deviation (DVD) is characterized by elevation, abduction and excyclotorsion of the nonfixing eye without corresponding hypotropia in the other eye. It is demonstrated by upward drifting and outward movement of the occluded eye on cover testing (1). DVD is usually, but not always, bilateral but asymmetrical. In addition to DVD, inferior oblique over action (IOOA) is also responsible for excessive elevation of one or both eyes but only in adduction ${ }^{(2)}$.

Several different procedures have been used with varying success to surgically manage DVD. In the past, bilateral large (symmetrical or asymmetrical) inferior rectus resections were advocated but, in recent years, this procedure has been abandoned by many surgeons ${ }^{(3,4)}$. Currently, two methods have been preferred, particularly when both DVD and IOOA are present, and these are anterior transposition of the inferior oblique muscle (ATIO) and myectomy of the inferior oblique muscle (MIO) $(5,6,7)$.

Anterior nasal transposition (ANT) is a relatively new procedure ${ }^{\mathbf{8 , 9})}$, in which the insertion is transposed to a location over the nasal half of the inferior rectus muscle typically $2 \mathrm{~mm}$ nasal to the nasal border of the inferior rectus muscle and $2 \mathrm{~mm}$ posterior to the inferior rectus insertion). The inferior oblique is thus transformed from an extorter into an intorter and from an elevator to a depressor. The ANT 
can be used to eliminate or reduce severe excyclotorsion. An advantage of this procedure over temporal anterior transposition is that it avoids Ante-elevation syndrome ${ }^{(9.10)}$. Good outcomes have also been reported in cases of overelevation in adduction combined with DVD. This success is likely due to the fact that the ANT procedure makes the inferior oblique muscle into a tonic depressor ${ }^{\text {(11). }}$

The objective of this study is to compare the results of anterior temporal transposition (ATIO) in comparison to anterior nasal transposition (ANT) of the inferior oblique muscle in patients who had DVD with IOOA.

\section{PATIENTS AND METHODS Patients}

This study was carried on 50 eyes of 28 patients with DVD of at least 10 or more prism diopter $(\Delta)$ in one or both eyes with IOOA that required surgery. The selection criteria for inclusion in the study were the patients with manifest or latent DVD, with concomitant IOOA. Exclusion criteria were patients who had paretic or restrictive strabismus, any prior surgery for the oblique muscle, vertical rectus muscle or concurrent vertical off-setting of the horizontal rectus muscles as well as patients with any systemic disorder or syndrome that might have affected extraocular muscles .Patients divided into two groups according to the procedure. Group A ( 25 eyes of 15 patients was managed by anterior temporal transposition (ATIO) and Group B (25 eyes of 13 patients) was managed by anterior nasal transposition.

DVD was measured by the method described by Burke $\boldsymbol{e t}$ al. ${ }^{(\mathbf{1 2})}$, using a prism and an alternate covering test in which the eyes in primary position was fixed at an adjustable target at a distance of $6 \mathrm{~m}$ and have full refractive corrections, when these was worn any concurrent horizontal deviation was neutralized using a horizontal prism. Subsequently, DVD in the other eye was measured in the same way. We evaluated any true hypertropia in primary eye position and in side gazes to distinguish between IOOA and DVD Oblique muscle function was estimated on a grading scale of $1+$ to $4+$ (over action) based on eye movements in an upward, a downward and a side gaze. Grade 1+ represented $1 \mathrm{~mm}$ of higher elevation of the adducting eye in gaze up and to the side. Grade $4+$ indicated $4 \mathrm{~mm}$ of higher elevation.

\section{Surgical Treatment}

All surgeries were done by the authors. The inferior oblique muscle was approached through the conjunctiva and Tenon's capsule by an inferior-temporal fornix incision. During the procedure, the lateral rectus muscle was isolated by a muscle hook. The inferior oblique muscle was exposed by placing a small Steven's hook along the inferior border of the lateral rectus muscle and a large Von Graefe hook was placed directly against sclera to be inserted posteriorly under the inferior oblique muscle. The Von Graefe hook was properly positioned perpendicular to the inferior oblique muscle fibers under the entire width of the inferior oblique muscle raising the hook was allow visualization of the area between the inferior oblique and sclera. Once the posterior border of the inferior oblique was identified by direct visualization, a Steven's hook was placed behind the posterior border. The inferior oblique muscle was isolated from its fascial attachments both anteriorly and posteriorly. A 6-0, suture (Vicryl) was passed through the muscle in group A and 5-0 Mersiline (Nonabsorbable) suture in group B to avoid retraction and slippage of new muscle insertion as recommended by Stager $\boldsymbol{e t} \boldsymbol{a l} .{ }^{(9)}$. The inferior oblique muscle has been secured with a doublearm suture and is being disinserted with the blunt Westcott scissors. After the inferior oblique muscle is disinserted, the muscle is reattached to the sclera. In temporal procedure reattached through sclera by using the crossedswords technique so that the new insertion lay lateral to and collinear with the inferior rectus muscle insertion in nasal procedure the posterior-temporal fibers attached $2 \mathrm{~mm}$ nasal and $2 \mathrm{~mm}$ posterior to the nasal extent of the inferior rectus muscle insertion. The new insertion is not spread out, and its width was approximately $2 \mathrm{~mm}$ to $3 \mathrm{~mm}$.

The inferior oblique muscle was then inspected to ensure that no residual fibers remained that had not been anteriorly transposed. The conjunctiva was closed with 60 (Vicryl) suture. Post-operative follow up were recorded at 1,3, and 6 months. At last postoperative visit, DVD of 0-9 PD was considered a good result and 10-14 PD a fair result.

\section{Statistical analysis:}


The results were evaluated and analyzed using the computer program SPSS (IBM Corp, Armonk, NY, USA). Statistical significance was tested using paired $t$-test and Willcoxon test with $P$-value $<0.05$ was considered statistically significant.

\section{RESULTS}

In the group A (15 patients of 25 eyes) the patients ages ranged from 6 to 30 years old and the mean age was 21.5 with standard deviation of \pm 4.5 . Nine patients $(60 \%)$ were females and $6(40 \%)$ patients were males. Eight patients had bilateral DVD. Preoperatively DVD angle was measured between 10 and $25 \Delta$ (mean, $21.1 \pm 4.3 \Delta) 14(56 \%)$ eyes had DVD $\leq$ $15 \Delta$, and the remaining (44\%) had DVD $>15 \Delta$.

In the group $B$ (13 patients of 25 eyes) the patients ages ranged from 8 to 31 years old and the mean age was 15.4 with standard deviation of \pm 3.7 . Eight $(53 \%)$ patients were females and $5(47 \%)$ patients were males. Nine $(81 \%)$ patients had bilateral DVD, preoperatively DVD angle was measured between 10 and $25 \Delta$ (mean, 19.4 $\pm 4.5 \Delta$ ), 14 (56 $\%$ ) eyes had DVD $\leq 15 \Delta$, and the remaining (44\%) had DVD $>15 \Delta$. Postoperatively DVD angle was measured between 0 and $5 \Delta$ (mean, $1.17 \Delta$ ). Mean follow-up was $20.4 \pm 4.5$ months for both groups.

All patients in both groups had preoperative inferior oblique over action. Mean pre- and post-operative IOOA in both groups are shown in (Table 1). In both groups, improvement of IOOA was statistically significant $(P<0.001)$ although difference between both groups was statistically insignificant $(P \geq 0.05)$. Persistent IOOA $(+1)$ was observed postoperatively in two eyes in each group. In ANT group, two patients, was developed post-operative IO under action $(-1)$.

Table (1): Grading of IOOA in both groups

\begin{tabular}{|c|c|c|}
\hline $\begin{array}{c}\text { Grading of } \\
\text { IOOA }\end{array}$ & Group A & Group B \\
\hline
\end{tabular}

\begin{tabular}{|c|c|c|}
\hline$+2-+3$ & $\begin{array}{c}13 \text { Eyes } \\
59 \%\end{array}$ & $\begin{array}{c}12 \text { Eyes } \\
53 \%\end{array}$ \\
\hline+4 & 7 Eyes $41 \%$ & $\begin{array}{c}8 \text { Eyes } \\
47 \%\end{array}$ \\
\hline \multicolumn{3}{|c|}{$\begin{array}{l}\text { IOOA: inferior oblique over action. } \\
+2 \text { represented } 2 \mathrm{~mm} \text { of higher elevation of } \\
\text { the adducting eye in gaze up and to the side. } \\
\text { Grade +4 indicated } 4 \mathrm{~mm} \text { of higher } \\
\text { elevation. }\end{array}$} \\
\hline
\end{tabular}

In group A (ATIO) was done isolated in nine patients, combined with horizontal muscle surgery in four patients. Three patients who underwent combined ATIO and horizontal muscle surgery were esotropic. They underwent ATIO combined with bimedial rectus recession (average $5.5 \pm 0.5 \mathrm{~mm}$ ), which resulted in improvement of their esotropia from 35 $\pm 5.02 \mathrm{PD}$ preoperatively to $5.5 \pm 3.4 \mathrm{PD}$ and one exotropic patient underwent ATIO combined with bilateral rectus recession $(7 \mathrm{~mm})$ which resulted in improvement of exotropia from 45 PD preoperatively to $5 \mathrm{PD}$.

In group B (ANT) was done isolated in seven patients, with horizontal surgery in five patients. In patients who underwent combined ANT and horizontal muscle surgery, three patients were esotropic with an average preoperative deviation of $38.6 \pm 5.9 \Delta$ and two patients had $40 \Delta$ exotropia. ANT combined with bimedial recession (average $5.9 \pm 0.5 \mathrm{~mm}$ ) were done to esotropic patients, which resulted in an average post-operative deviation of $5 \pm .9$ $\Delta$ ET. The exotropic patients underwent combined ANT with (average $6.5 \pm 0.5 \mathrm{~mm}$ ) mm bilateral lateral rectus recession that resulted in $10 \Delta$ XT postoperatively.

In both groups preoperatively, two patients, one in each group had no fusion with worth's four dot test. All other patients had different grades of stereopsis 'ranging from 40 to 800 arcsec'.

Assessment of postoperative deviation in terms of the mean value of prism dioptres showed that the surgical technique were successful because the differences between preand postoperative values were significant Figure (1). 
Comparison Between Temporal Versus Nasal Anterior Transposition of the Inferior Oblique...

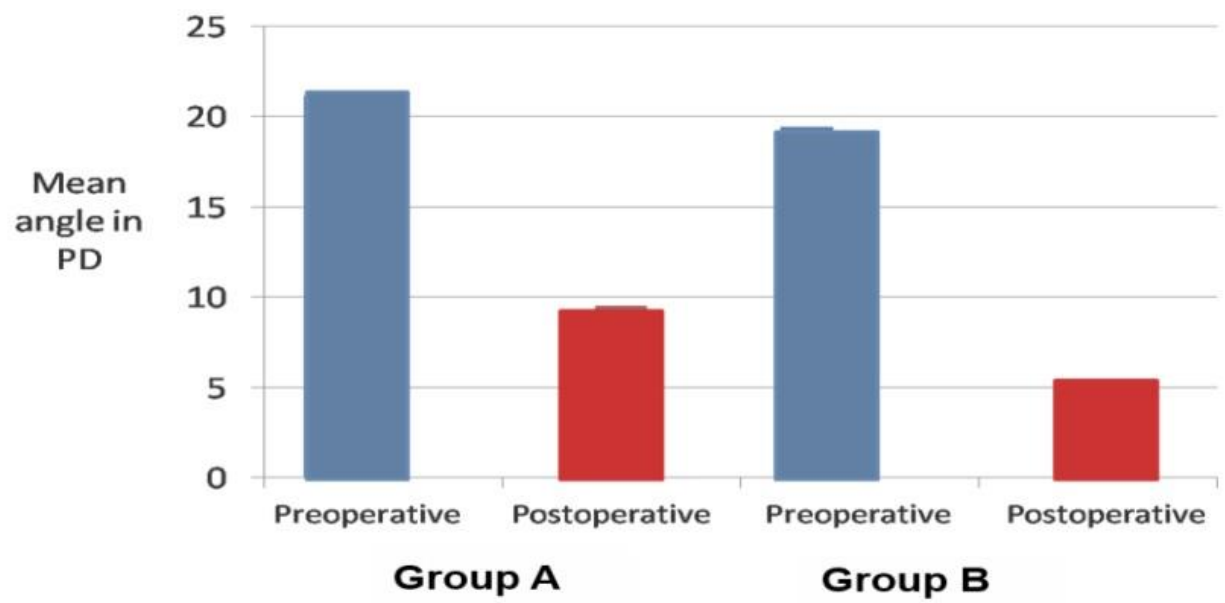

Figure (1): Preoperative and postoperative deviation in terms of the mean value of prism dioptres.

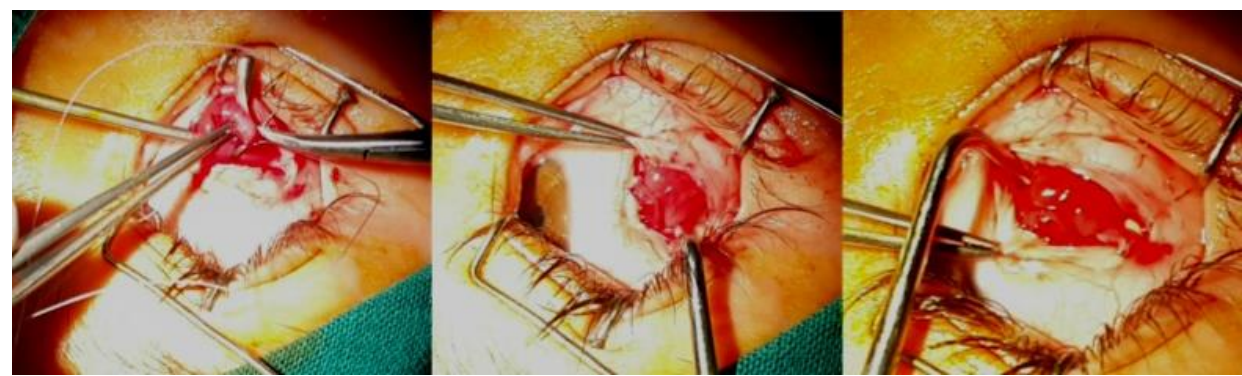

Figure (2): Anterior temporal transposition of IO in RT eye.

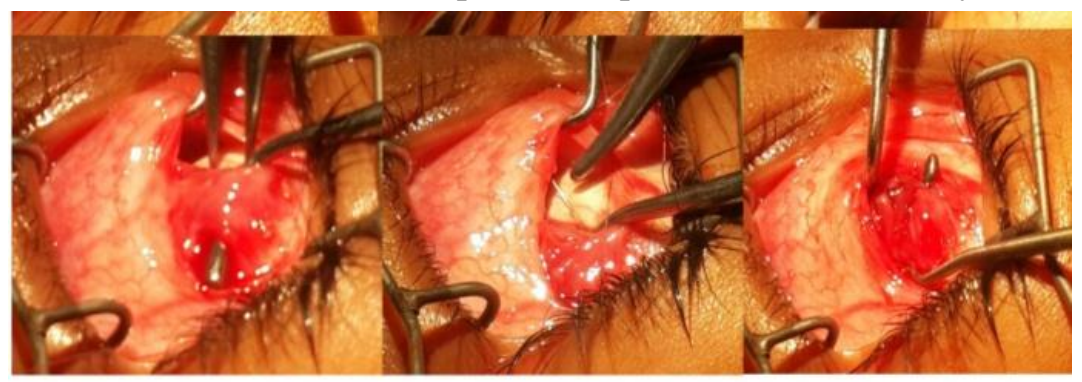

Figure (3): Nasal anteriorization of IO mucsle in RT eye.

In group A preoperatively DVD angle in primary position was averaged $21.11 \pm 4.4 \Delta$ $(10-25 \Delta), 26.35 \pm 4.3 \Delta(17-32 \Delta)$ in adduction, and 5.5 $\pm 2.02 \Delta(4-7 \Delta)$ in abduction. After the operation, DVD was averaged $9.5 \pm 3.79 \Delta(5-$ $15 \Delta)$ in primary position $(P<0.001), 4.8 \pm 1.94 \Delta$ $(2-7 \Delta)$ in adduction $(P<0.001)$, and 3.16 \pm 1.09 $\Delta(0-5 \Delta)$ in abduction $(P>0.05)$.

In group $B$ preoperatively DVD angle was averaged $19.4 \pm 4.5 \Delta(10-25 \Delta)$ in primary position, 27.7 $\pm 5.3 \Delta(19-34 \Delta)$ in adduction, and $3.5 \pm 1 \Delta .1(2-5 \Delta)$ in abduction. After the operation, DVD was averaged $5.9 \pm 1.19 \Delta(2-6$ $\Delta)$ in primary position $(P<0.001), 5.1 \pm 1.5 \Delta(4$ $8 \Delta)$ in adduction $(P<0.001)$, and $1.40 \pm 1.2 \Delta(1-$ $3 \Delta)$ in abduction $(P<0.001)$.
In-group B correction in primary position and in abduction, which was statistically significant $(P \leq 0.05)$ while in adduction, there was insignificant difference in correction of DVD among both groups $(P>0.05)$.

In group $\mathrm{B}$, two patients developed hypotropia of 5 and $6 \Delta$. Limited elevations in abduction developed after surgery in 3 patients in group A, the incidence of recurrence after 24 months was 2 eyes $10 \%$ in group A and one eye $5 \%$ in group B.

\section{DISCUSSION}


Anteriorization of the inferior oblique muscle (ATIO) for management of DVD with IOOA was evaluated by several authors (11-13) these studies have shown that (ATIO) is effective in controlling DVD in the majority of cases and more effective in management of DVD with IOOA. The current study was designed to compare the results of anterior temporal transposition versus anterior nasal transposition of the inferior oblique muscle in patients who had DVD with IOOA.

In our study good outcomes were achieved by both methods in management of IOOA. Persistent IOOA (grade +1) was observed postoperatively in two eyes in each group after 6 months. Postoperatively three eyes in group A and four eyes in group B presented by $\mathrm{IO}$ under action ranged from grade -1 to -3 in first postoperative visits. All cases had IO under action improved along follow up period ( $100 \%$ of patients). There was marked improvement in symmetry of eye version and IO over action at 6 months and up to 24 months of follow up.

Mims and Woods ${ }^{(14)}$ claimed that ATIO changes IO action from an elevator to a depressor due to Lockwood's ligament effect. Elliot and Nankin ${ }^{(15)}$ compared ATIO to IO recession in treating IOOA and concluded that ATIO changes the action of IO from an elevator to a depressor. Mims and Woods ${ }^{(14)}$ noted improvement in DVD and IOOA when evaluating bilateral ATIO in treatment of IOOA patients. Burke et al. ${ }^{(\mathbf{1 2})}$ found that ATIO was effective in controlling DVD in 19 out of 22 eyes.

In group A anterior temporal transposition of IO improved vertical devotion up to $20 \Delta$ in primary position. Two cases developed residual vertical deviation $10 \Delta$ (preoperative 25-30 $\Delta$ ), which need superior rectus recession.

Limited elevation in abduction developed after surgery in 3 patients in group A. Kushner ${ }^{(16)}$ has shown that the limited elevation in abduction, a complication of ATIO, occurs when the transposition of the inferior oblique muscle anterior to the inferior rectus muscle insertion is greater than $1 \mathrm{~mm}$. This complication, which results in either a $\mathrm{Y}$ or $\mathrm{V}$ pattern, is more likely to happen if the inferior oblique insertion is spread out when being reattached to the globe. ATIO converts the posterior fibers of that muscle segment to a tonic depressor in the primary position and an anti-elevator limiting up gaze to $30-35^{\circ}(\mathbf{1 3 , 1 4 )}$. After ATIO, the normal increased innervations of the IO muscle on supraduction produces a powerful force vector directed inferiorly, effect termed antielevating ${ }^{(15)}$. This antielevating force can produce over action of the contralateral elevators in adduction that mimics recurrent or new over action of the IO muscle of the other eye ${ }^{(16,17)}$.

Guemes ${ }^{(19)}$ suggested that unilateral anterior transposition procedure resulted in a mean reduction in the vertical deviation of 18 $\Delta$.Weakening of the inferior oblique muscle produces 5 to $10 \Delta$ reduction in hyperdeviation in the primary position and up to $20 \Delta$ reduction in hyperdeviation in the field of action of this muscle. Unilateral anterior temporal transposition of IO had been done in four cases in group I, two cases developed contralateral DVD.

In the current study in group A, Preoperative DVD $\leq 15 \Delta$ had excellent outcome (0-5 $\Delta)$. Black ${ }^{(17)}$ and Engman ${ }^{(18)}$ reported excellent results of ATIO in $56 \%$ of cases with small DVD and in $25 \%$ of cases with large DVD $(>15 \Delta)$. Milot et al. ${ }^{(20)}$ concluded that ATIO is more effective in eliminating IOOA (100\% of cases) but the procedure is less predictable for DVD with $29.4 \%$ recurrences during a follow-up period of 28.2 months. Coats (21) results also were less encouraging regarding ATIO in treatment of DVD.

In group B ANT IO improved vertical deviation up to $20 \Delta$ in primary position. Two cases developed residual vertical deviation $10 \Delta$ (preoperative 25-30 $\Delta$ ). Awadein ${ }^{(22)}$ suggested that IO over action after ANT disappeared completely in $80 \%$ with no significant under-or over-correction. $20 \%$ of patients had consecutive IO under action on both sides.

Stager et al. ${ }^{(8)}$ in 2001 proposed transposing IO not only anteriorly but also nasally to the nasal border of IR. In this technique, the IO is positioned anterior to $x$ axis and nasal to $y$ axis, which changes IO from an elevator and extorter to a depressor and intorter in adduction. Furthermore, in 2003, Stager et al. ${ }^{(9)}$ studied the effect of this new procedure on IOOA in a diverse group of patients. Among them, two cases had DVD associated and ANT resulted in elimination of both. Fard (11) concluded that ANT was effective in controlling DVD, IOOA, and V pattern in his 10 patient's study with $53 \%$ of his patients with 
large DVD achieved an excellent outcome and $47 \%$ had a fair outcome. In group B of the current study, only $35 \%$ of patients with DVD>15 PD achieved an excellent outcome and $62.5 \%$ had a good outcome. Our ANT results exactly match that of Fard ${ }^{(11)}$ study in small DVD patients where $100 \%$ of patients achieved an excellent outcome.

Standard anterior transposition of the inferior oblique muscles may also less effective in patients with larger amounts of DVD. ANTIO resulted in excellent outcome (residual DVD of 0-5 $\Delta$ ) in $60 \%$ of patients, up to $53 \%$ of eyes with DVD of $15 \Delta$ or more For patients who had 0 to $15 \Delta$ of preoperative DVD, $100 \%$ had an excellent outcome.

Stager et al. ${ }^{(9)}$ proved that ANT procedure was performed with success both unilaterally or bilaterally. In the patients who underwent unilateral ANT, no specific problems in up gaze.

In comparison between the results of ATIO and ANT for management of DVD with IOOA; we cleared that, generally, both procedures are almost equally effective in controlling IOOA, hypertropia and DVD. ANT gives significantly better results for DVD in primary position and in abduction but less likely to develop antielevation, consecutive hypotropia and persistent IO under action also this finding was correlated with Fard study ${ }^{(23)}$ he found both procedures are effective in controlling true hypertropia in side gaze with no significant difference in between. Persistent IOOA was reported nearly equally in both groups.

In this study, we did not observe any significant effect on lower lid positions with IO anterior transposition. Some studies have reported that IO transposition of $1 \mathrm{~mm}$ or more anterior to the inferior rectus muscle insertion as well as the lateral spreading of the posterior fibers more than $2 \mathrm{~mm}$ at the new insertion are risk factors for complications of this surgery such as anti-elevation syndrome and hypotropia $(\mathbf{2 4 , 2 5 )}$. The lower lid elevation and fullness in lower lid on upgaze also noted more in this augmented anteriorization procedures ${ }^{(27,28)}$.

In conclusion, the comparison between the two surgical methods for treating DVD with IOOA showed that both procedures were effective in correcting dissociated vertical deviation and inferior oblique muscle over action, but nasal transposition of the inferior oblique muscle is a more effective surgery with greater improvement in the degree of inferior oblique over action and less likely to develop antielevation, consecutive hypotropia and persistent IO under action.

\section{REFERENCES}

1. Kommerll G, Matteus S (1996): Revised fixation test to differentiate between dissociated and non dissociated strabismus. Strabismus, 4(1):3-9.

2. Caputo AR, Santiago AP (1996): Bilateral anterior transposition of the inferior oblique for dissociated vertical deviation in congenital esotropia. Am Orthoptic J., 46: 133-142.

3. Esswein MB, von Noorden GK, Coburn A (1992): Comparison of surgical methods in the treatment of dissociated vertical deviation. Am J Ophthalmol., 113: 287290.

4. Bacal DA (1992): Anterior transposition of the inferior oblique muscle for both dissociated vertical deviation and/or inferior oblique over action: results of 94 procedures in 55 patients. Binocular Vision Eye Muscle Surg Q., 7:219-25.

5. Santiago AP, Isenberg SJ, Apt L, Roh YB (1997): The effect of anterior transposition of the inferior oblique muscle on ocular torsion. J AAPOS., 1:191-196.

6. Black BC (1997): Results of anterior transposition of the inferior oblique muscle in incomitant dissociated vertical deviation. J AAPOS., 1:83-87.

7. Gonzalez C, Klein B (1993): Myectomy and anterior transposition of the inferior oblique: a new surgical procedure and its results in 49 operations. Binoc Vis Eye Muscle Surgery Qtrly., 8:249-258.

8. Stager DR, Beauchamp GR, Stager DR (2001): Anterior and nasal transposition of the inferior oblique muscle: A preliminary case report on a new procedure. Binocul Vis Strabismus Qtrly., 16:43-4.

9. Stager DR, Beauchamp GR, Wright WW, Felius J, Stager DR (2003): Anterior and nasal transposition of the inferior oblique muscles. J AAPOS., $7: 167-73$. 
10. Hussein MA, Stager DR, Sr, Beauchamp GR, Stager DR, Felius J (2007): Anterior and nasal transposition of the inferior oblique muscles in patients with missing superior oblique tendons. J AAPOS., 11:29-33.

11. Fard MA (2010): Anterior and nasal transposition of the inferior oblique muscle for dissociated vertical deviation associated with inferior oblique muscle over action. J AAPOS., 14:35-8.

12. Burke JP, Scott WE, Kutshke PJ (1993): Anterior transposition of the inferior oblique muscle for dissociated vertical deviation. Ophthalmology, 100: 245-250.

13. Gonzalez C, Klein B (1993): Myectomy and anterior transposition of the inferior oblique: a new surgical procedure and its results in 49 operations. Binoc Vis Eye Muscle Surgery Qtrly., 8: 249-258.

14. Mims JL III, Wood RC (1989): Bilateral anterior transposition of the inferior obliques. Arch Ophthalmol., 107: 41-44.

15. Elliott RL, Nankin SJ (1981): Anterior transposition of the inferior oblique. $\mathrm{J}$ Pediatr Ophthalmol Strabismus, 18: 35-38.

16. Kushner BJ (1997): Restriction of elevation in abduction after inferior oblique anteriorization. J AAPOS., 1:55-62.

17. Black BC (1997): Results of anterior transposition of the inferior oblique muscle in incomitant dissociated vertical deviation. J AAPOS., 1: 83-87.

18. Engman JH, Egbert JE, Summers CG, Young TL (2001): Efficacy of inferior oblique anterior transposition placement grading for dissociated vertical deviation. Ophthalmology, 108: 2045-2050.

19. 19. Guemes A, Wright, KW (1998): Effect of Graded Anterior Transposition of the Inferior Oblique Muscle on Versions and Vertical Deviation in Primary Position, J AAPOS., 2:201-6.

20. Milot JM, Tremblay C, Ouellette C (1994): Anterior transposition of the inferior oblique for dissociated vertical deviation with inferior oblique over action. Can J Ophthalmol., 29: 284-287.

21. Coats DK, Paysse EA, Stager DR (2000): Surgical management of V-pattern strabismus and oblique dysfunction in craniofacial dysostosis. J AAPOS., 4: 338342.

22. AwadeinA R (2009): Comparison between Myectomy and Nasal transpositionof Inferior Oblique Muscle in Inferior Oblique Over action. Kasr El Aini Med J., 15(19):102-106.

23. Fard MF (2016): Anterior transposition $v s$ anterior and nasal transposition of inferior oblique muscle in treatment of dissociated vertical deviation associated with inferior oblique overaction. Eye, 30(4):522-528.

24. Kushner BJ (1997): Restriction of elevation in abduction after inferior oblique anteriorization. J AAPOS., 1:55-62.

25. Ziffer AJ, Isenberg SJ, Elliott RL, Apt L (1993): The effect of anterior transposition of the inferior oblique muscle. Am $\mathrm{J}$ Ophthalmol., 116:224-7.

26. Farvardin M, Bagheri M, Pakdel S (2013): Combined resection and anterior transposition of the inferior oblique muscle for treatment of large primary position hypertropia caused by unilateral superior oblique muscle palsy. J AAPOS., 17:37880.

27. Farvardin M, Nazarpoor S (2002): Anterior transposition of the inferior oblique muscle for treatment of superior oblique palsy. J Pediatric Ophthalmoly strabismus, 39(2):100-4. 